\title{
Large-Scale Production of Microcrystals and Precipitates of Proteins and Their Complexes
}

\author{
Monique Chan-Huot, ${ }^{*}, \dagger, \S, \S, \perp, \perp$ Luminita Duma, ${ }^{\dagger, \ddagger}, \S$ Jean-Baptiste Charbonnier, ${ }^{\#}$ \\ Jose-Enrique Herbert-Pucheta, ${ }^{\dagger, \ddagger, \S}$ Liliane Assairi, ${ }^{\|, \perp}$ Yves Blouquit, ${ }^{\prime, \perp}$ Daniel Abergel, ${ }^{\dagger},+, \S$ \\ and Geoffrey Bodenhausen ${ }^{\dagger, \ddagger, \S, \text { II }}$ \\ †Département de Chimie, Ecole Normale Supérieure, 24 rue Lhomond, 75231 Paris cedex 05, France \\ ${ }^{\ddagger}$ Université Pierre et Marie Curie, Paris, France \\ ${ }^{\S}$ UMR 7203, Laboratoire des BioMolécules, CNRS/UPMC/ENS, Paris, France \\ "Institut Curie, 91405 Orsay, France \\ ${ }^{\perp}$ INSERM U759, 91405 Orsay, France \\ ${ }^{\#}$ UMR 8221, Laboratoire de Biologie Structurale et Radiobiologie, iBiTec-S, CEA, 91191 Gif-sur-Yvette, France \\ II Institut des Sciences et Ingénierie Chimiques, Ecole Polytechnique Fédérale de Lausanne, Batochime, 1015 Lausanne, Switzerland
}

ABSTRACT: The optimum conditions for the formation of plate-like and urchin-like microcrystals of biomolecules and their transfer to rotors for solid-state NMR spectroscopy depend on a variety of factors, of which minimizing the manipulation of the microcrystals and storing the sample for several months at $277 \mathrm{~K}\left(4{ }^{\circ} \mathrm{C}\right)$ play an important role. Three biological systems were investigated: Hen Egg-White (HEW) lysozyme (129 residues), the lengthened C-terminal domain (LCter) of Human centrin 2 (89 residues), and the complex

between the C-terminal domain (Cter) of Human centrin 2 (79 residues) and the P17-XPC peptide (17 residues).

\section{INTRODUCTION}

Microcrystals of proteins that are suitable for solid-state NMR can be produced in considerable amounts and much more quickly than single crystals for X-ray diffraction. Microcrystals are not only relevant for the delivery of biopharmaceuticals ${ }^{1}$ but also for the characterization of biophysical properties of proteins such as local motions that are believed to be pertinent for their function. Several methods have been developed to study proteins in microcrystalline form, including differential scanning calorimetry, ${ }^{2}$ infrared spectroscopy combined with one or two-dimensional Fourier transformation, ${ }^{3-6}$ mass spectrometry, ${ }^{7,8}$ electron microscopy, ${ }^{2,9}$ X-ray powder diffraction, ${ }^{9,10}$ atomic force microscopy, ${ }^{11,12}$ and solid-state nuclear magnetic resonance (NMR) spectroscopy for site-specific investigations of protein structure ${ }^{13}$ and dynamics. ${ }^{14}$ Besides, solid-state NMR (ssNMR) is so far the only technique capable of getting structural information and conformational dynamics of membrane proteins, amyloid fibrils, and other noncrystalline systems. ${ }^{15,16}$ The past decade has witnessed considerable instrumental and methodological progress in solid-state NMR. However, to date, only a handful of microcrystalline proteins prepared by dialysis, precipitation, vapor diffusion, or the batch method have been studied by solid-state NMR. ${ }^{17-28}$ This is in large part owing to the fact that obtaining microcrystals suitable for this technique is not easily achieved in routine.

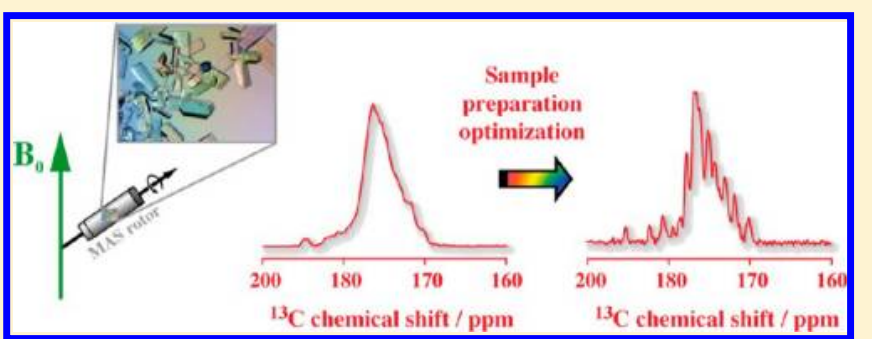

Solid-state NMR allows elucidating structural features of biological samples in a manner that is complementary to X-ray crystallography. In contrast to solution-state NMR, there are no limitations imposed by the solubility, and NMR spectra are not affected by the molecular weight. In addition, the use of spinrelaxation experiments on microcrystalline proteins opens new avenues for the investigation of internal dynamics on time scales that extend beyond the overall tumbling time of the molecule. In solution, the overall molecular tumbling of the molecule masks such internal motions. However, preparing samples of sufficient quality and quantity for solid-state NMR turns out to be a tremendously difficult task. Protein samples need to fulfill various requirements for solid-state NMR, which needs large quantities (on the order of $5 \mathrm{mg}$ ), homogeneity, low-salt concentration, adequate morphology of the microcrystals, and stability with respect to time and temperature variations. Moreover, fast and reproducible preparation protocols are desirable. Small rotors (i.e., 1.3 and $2.5 \mathrm{~mm}$ outer diameter) for fast and ultrafast spinning MAS experiments require robust filling methods. Using small diameter rotors enables faster sample spinning and therefore more efficient averaging of anisotropic interactions. Nevertheless, the

Received: September 20, 2012

Revised: October 31, 2012

Published: November 5, 2012 
smaller the rotor, the more challenging is its filling. Relatively low-salt concentrations are important to achieve efficient radiofrequency fields and therefore short pulse lengths. Indeed, ionic conductivity can lead to sample heating by radiofrequency irradiation $^{29}$ although new generations of low heat conductivity probes seem promising. Multidimensional NMR experiments are time-consuming, so that the samples need to be stable for several days at least. If the samples are not homogeneous, a superposition of the different conformations will lead to inhomogeneous line broadening ${ }^{30}$ and therefore poorly resolved resonances in the NMR spectra. Crystalline samples that contain molecules with a unique well-defined conformation give high-resolution solid-state NMR spectra. Only few examples in the literature show highly resolved spectra of microcrystalline proteins that are uniformly labeled with stable isotopes such as carbon-13, nitrogen-15, or deuterium. To the best of our knowledge, NMR spectra of microcrystals of proteins that form complexes with a peptide, another protein, or a nucleic acid have not been reported so far. The only examples of protein complexes investigated by solid-state NMR methods are pellets of proteoliposomes of a scorpion toxinmembrane protein in the presence of a potassium channel analogue $^{31}$ and pellets of the periplasmic disulfide-donor enzyme DsbA that is covalently bound to its oxidizing agent DsbB. ${ }^{27}$ We consider that these pellets are not crystalline on the micrometer scale. The highly resolved carbon-13 and nitrogen-15 CPMAS NMR spectra reveal a homogeneous sample, whereas the pellets stem from a centrifugation process rather than a classical crystallization process.

This article presents the development and optimization of several protein microcrystals preparation protocols: the Hen Egg-White (HEW) lysozyme (129 residues), the 89 residue (long) construct of the C-terminal domain (LCter) of Human centrin 2, and the complex between the C-terminal domain (Cter) of Human centrin 2 (79 residues) and the P17-XPC peptide (17 residues). The latter Cter HsCen2/P17-XPC complex is a good model of an intermediate that plays a role in the DNA nuclear excision repair process involving Human centrin 2 and Xeroderma Pigmentosum group C (XPC) protein with hHR23B. ${ }^{32}$ Slow internal dynamics in the Cter HsCen2/ P17-XPC complex (on micro- to millisecond time scales) was studied in solution by relaxation methods based on two-spin multiple-quantum coherences. ${ }^{33}$ The present work represents a preliminary step toward a detailed study of the internal dynamics of the complex by solid-state NMR spectroscopy. Here, we describe robust protocols to prepare microcrystals of protein-peptide complexes with dimensions in the range of a few micrometers. The present protocol is designed to fulfill the requirements of solid-state NMR but can also be used for other spectroscopic and biophysical techniques.

\section{EXPERIMENTAL PROCEDURES}

The concentrations of the protein samples were evaluated with a Nanodrop apparatus against the corresponding buffers. At $280 \mathrm{~nm}$, the molar extinction coefficients were $37970,1490,5500,11369$, and 10 $377 \mathrm{M}^{-1} \cdot \mathrm{cm}^{-1}$ for HEW lysozyme, Cter HsCen2, P17-XPC, Cter HsCen2/P17-XPC complex, and LCter HsCen2, respectively. All extinction coefficients were determined by the ProtParam analysis tool of the ExPASy database, based on knowledge of the amino acid composition of the proteins. ${ }^{34-37}$ They correspond to the molar extinction coefficients of the native proteins. The differences between the native and denatured molar extinction coefficients are small.

Cter HsCen2: Protein Expression and Purification. The recombinant protein Cter HsCen2 $\left(\mathrm{Thr}^{94}-\mathrm{Tyr}^{172}\right)$ was overexpressed in a BL21(D3)/pDIA17 Escherichia coli strain $^{38}$ and purified as described previously. ${ }^{39}$ For doubly labeled samples $\left({ }^{13} \mathrm{C}\right.$ and $\left.{ }^{15} \mathrm{~N}\right)$, we used $4 \mathrm{~L}$ of minimum medium (M9) containing ${ }^{15} \mathrm{NH}_{4} \mathrm{Cl}\left(1 \mathrm{~g} \cdot \mathrm{L}^{-1}\right)$ and ${ }^{13} \mathrm{C}_{6}$-glucose $\left(3 \mathrm{~g} \cdot \mathrm{L}^{-1}\right)$ as the sole source of nitrogen and carbon, respectively, and supplemented with $75 \mu \mathrm{g} \cdot \mathrm{mL}^{-1}$ of kanamycin and 30 $\mu \mathrm{g} \cdot \mathrm{mL}^{-1}$ of chloramphenicol. The bacteria were grown at $310 \mathrm{~K}$ (37 ${ }^{\circ} \mathrm{C}$ ). The value of the optical density (OD) was intentionally allowed to reach 1.5 , while classical protocols stop at $0.5-0.8$. This permits to gain in mass but diminishes the fitness of the bacteria. Besides, it prevents healthy bacteria (grown at OD 0.5-0.8) from destroying the expressed protein. The expression was induced with $0.2 \mathrm{mM}$ isopropyl-beta-D-thiogalactoside (IPTG), and growth was prolonged overnight at $310 \mathrm{~K}$. The protein was purified according to the procedure previously described. ${ }^{40}$ The purification yielded $18 \mathrm{mg}$ per liter of E.coli culture for the doubly labeled Cter HsCen2 protein, which was lyophilized and stored at $193 \mathrm{~K}\left(-80{ }^{\circ} \mathrm{C}\right)$.

Preparation of the Cter HsCen2/P17-XPC Complex in Solution. The lyophilized protein was dissolved in $20 \mathrm{mM}$ Tris at $\mathrm{pH} 6.5$ and 7.5 at various concentrations $(2,2.5$, and $3 \mathrm{mM})$. The concentration of $\mathrm{NaCl}$ was varied between 100 and $400 \mathrm{mM}$ and $\mathrm{CaCl}_{2}$ between 3 and $10 \mathrm{mM}$. The P17-XPC peptide AcNWKLLAKGLLIRERLKR-NH $\mathrm{NH}_{2}$ (95\% purity) was purchased from GeneCust (Dudelange, Luxembourg). All new batches were dissolved in Milli-Q water and lyophilized before use. Stock solutions were prepared in Milli-Q water at different concentrations $(2-6 \mathrm{mM})$ and stored at $193 \mathrm{~K}$. Complex solutions with different molar protein/ peptide ratios $1: 1,1: 1.2$, and $1: 2$ were obtained by mixing adequate volumes of protein and peptide stock solutions. The $\mathrm{pH}$ of the complex solutions was adjusted to 4 .

The choice of the Tris buffer may seem questionable as its effective $\mathrm{pH}$ lays in the range of 7 to 9 , while the isoelectric point is estimated to 4.6 for the Cter HsCen2 domain and to 5.2 for the Cter HsCen2/ P17-XPC complex. ${ }^{37}$ The $\mathrm{pH}$ of the solution dropped to 4.8 upon the addition of the lyophilized protein to $20 \mathrm{mM}$ Tris at $\mathrm{pH} 7.5$, but microcrystals of the 1:2 complex were still obtained. Actually, the initial $\mathrm{pH}$ of the protein can vary in the $4-8$ range without impeding crystallogenesis as it is adjusted to 4 before adding the precipitating agent.

High-Throughput Crystallization. Initial crystallization screenings were carried out taking advantage of the high-throughput crystallization facility at the EMBL in Grenoble. The complex was screened at three different Cter HsCen 2 concentrations (3, 6, and 12 $\mathrm{mg} \cdot \mathrm{mL}^{-1}$ ) against 576 crystallization cocktails (plates 1 and 6 from Qiagen Nextal and plates 2, 3, 4, and 8 of Hampton Research). The molar protein/peptide ratio was 1:2. The following three conditions gave crystals at $293 \mathrm{~K}\left(20{ }^{\circ} \mathrm{C}\right)$ : (a) protein concentration of 12 $\mathrm{mg} \cdot \mathrm{mL}^{-1}, 0.5 \mathrm{M}$ ammonium sulfate, $0.1 \mathrm{M}$ HEPES at $\mathrm{pH} 7.5$, and $30 \%$ $\mathrm{v} / \mathrm{v} \mathrm{MPD}$, (b) protein concentration of $6 \mathrm{mg} \cdot \mathrm{mL}^{-1}, 0.8 \mathrm{M}$ sodium/ potassium phosphate at $\mathrm{pH} 8.2,32 \mathrm{mM}$ sodium dihydrogen phosphate monohydrate, and $77 \mathrm{mM}$ dipotassium hydrogen phosphate, and (c) protein concentration of $6 \mathrm{mg} \cdot \mathrm{mL}^{-1}, 1.0 \mathrm{M}$ sodium/potassium phosphate at $\mathrm{pH} 8.2,40 \mathrm{mM}$ sodium dihydrogen phosphate monohydrate, and $0.96 \mathrm{M}$ dipotassium hydrogen phosphate. The crystallization experiments were set up with a Cartesian PixSys 4200 crystallization robot (Genomic Solutions, UK) using Greiner Crystal Quick plates (flat bottom, untreated). The imaging system is a RoboDesign Minstrel III (Rigaku Msc, UK) at $293 \mathrm{~K}$ and a Formulatrix RockImager (Formulatrix, Inc., USA) at $277 \mathrm{~K}$. Protocols are described in the literature. ${ }^{41}$

Low-Salt Screening Conditions. High-throughput screening resulted only in high-salt conditions that are not suitable for solidstate NMR experiments. Therefore, further screening with Stura type precipitating agents was performed on triplets of $2 \mu \mathrm{L}$ volumes of complex at different concentrations and of precipitating agent by the sitting-drop vapor-diffusion method. The solutions were either purchased from Molecular Dimensions (Suffolk UK) or homemade. In the latter case, the PEG was filtered, and buffer solutions containing $0.05 \% \mathrm{NaN}_{3}$ were filtered through a $0.2 \mu \mathrm{m}$ filter. The boxes were prepared at room temperature, while the complex solutions were kept on ice. Two precipitating agents permitted us to obtain microcrystals: 


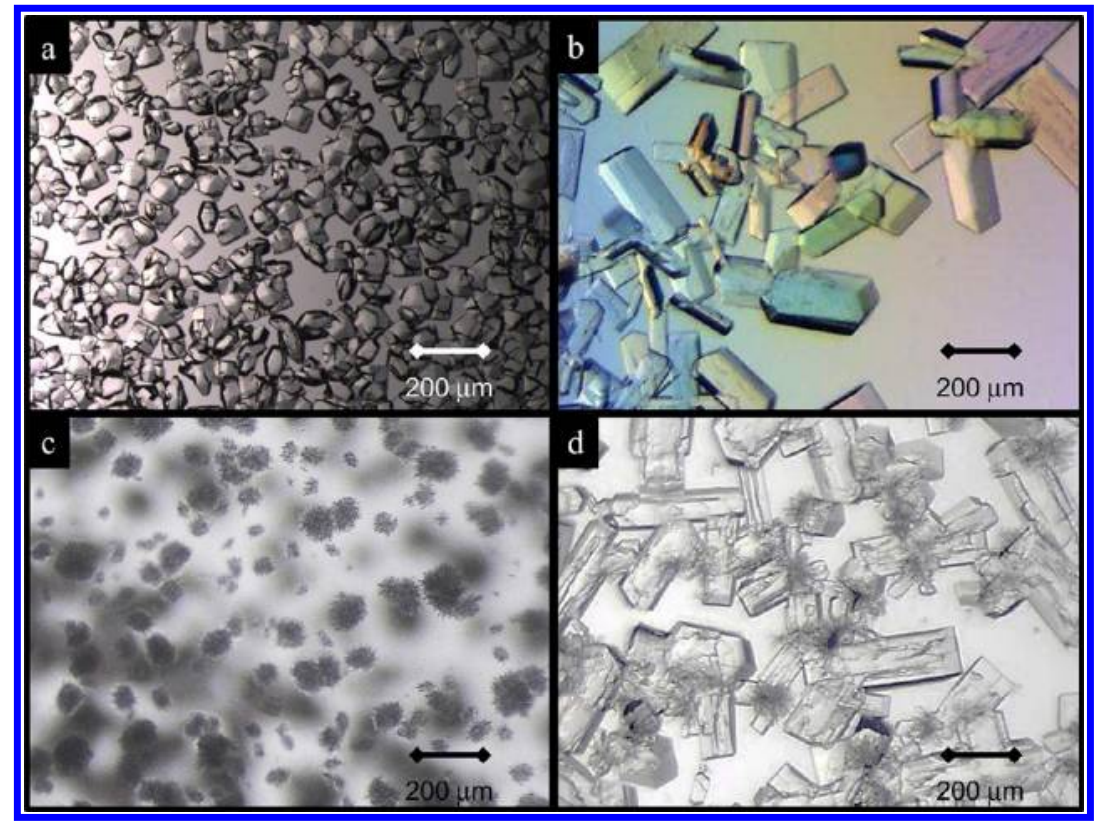

Figure 1. (a) Crystals of Hen Egg-White (HEW) lysozyme obtained by depositing $100 \mu \mathrm{L}$ of the mother solution $\left(100 \mathrm{mg} \cdot \mathrm{mL}^{-1}\right.$ in $100 \mathrm{mM} \mathrm{sodium}$ acetate at $\mathrm{pH} 4.5$ ) on a watch lens stored in a Petri dish containing $7.5 \mathrm{~mL}$ of a precipitating agent composed of $33 \% \mathrm{w} / \mathrm{v}$ PEG $2 \mathrm{k}, 6 \mathrm{mM}$ trisodium citrate, and $100 \mathrm{mM}$ sodium acetate at $\mathrm{pH}$ 4.5. (b) Plate-like crystals of Cter HsCen2/P17-XPC complex (molar ratio protein/peptide 1:2, 34 $\mathrm{mg} \cdot \mathrm{mL}^{-1}$ in $20 \mathrm{mM}$ Tris at $\mathrm{pH} 7.5,400 \mathrm{mM} \mathrm{NaCl}, 10 \mathrm{mM} \mathrm{CaCl}_{2}$ ) obtained by the batch method using $150 \mu \mathrm{L}$ of mother solution, $150 \mu \mathrm{L}$ of precipitating agent (42\% v/v PEG 600 in $0.2 \mathrm{M}$ imidazole malate at pH 5.5) and $50 \mu \mathrm{L}$ of paraffin oil to prevent evaporation. (c) Urchin-like crystals of Cter HsCen2/P17-XPC complex obtained by vapor diffusion of $4 \mu \mathrm{L}$ drops mother solution and $4 \mu \mathrm{L}$ of precipitating agent in a reservoir containing $700 \mu \mathrm{L}$ of precipitating agent. (d) Mixture of urchin-like and plate-like crystals of Cter HsCen2/P17-XPC complex obtained by the vapordiffusion method using volumes of $20 \mu \mathrm{L}$.

(1) $46 \% \mathrm{v} / \mathrm{v}$ PEG 400 in citrate buffer at $\mathrm{pH} 5.5$ and (2) $42 \% \mathrm{v} / \mathrm{v}$ PEG 600 in $0.2 \mathrm{M}$ imidazole malate at $\mathrm{pH}$ 5.5. Crystals appeared within 24 $\mathrm{h}$ when the boxes were stored at $277 \mathrm{~K}$ and after 3 days at $290 \mathrm{~K}$ only for a molar protein/peptide ratio of 1:2. Control experiments with the buffer alone or the protein alone did not lead to any crystals. Although dyeing the microcrystals with methylene blue was not conclusive, the plate-like microcrystals of the complex gave X-ray diffraction patterns with a resolution of $1.7 \AA$. After dissolving the microcrystals with $6 \mathrm{M}$ guanidinium hydrochloride, SDS PAGE gel electrophoresis gave a band at the same molecular mass as the complex solution. To test their stability, the microcrystals were stored at $310 \mathrm{~K}$ for $48 \mathrm{~h}$. The integrity of the microcrystals and possible changes in their morphology were monitored qualitatively with a visible-light microscope. We therefore chose $42 \% \mathrm{v} / \mathrm{v}$ PEG 600 in $0.2 \mathrm{M}$ imidazole malate at $\mathrm{pH} 5.5$ since no morphological modifications were observed.

Precipitates of the Cter HsCen2/P17-XPC Complex. A solution of the Cter HsCen2/P17-XPC complex was prepared as described above using a molar ratio of 1:2 of Cter HsCen2 (28 $\left.\mathrm{mg} \cdot \mathrm{mL}^{-1}, 3 \mathrm{mM}\right)$ in $20 \mathrm{mM}$ Tris at $\mathrm{pH} 7.5,400 \mathrm{mM} \mathrm{NaCl}$, and 10 $\mathrm{mM} \mathrm{CaCl}{ }_{2}$ with P17-XPC peptide $\left(13 \mathrm{mg} \cdot \mathrm{mL}^{-1}, 6 \mathrm{mM}\right)$ in Milli-Q water. Microcrystals were obtained either by the vapor-diffusion method or by the batch method by mixing equal volumes of the complex solution with the commercial Stura 1D (Molecular Dimensions, Suffolk UK) precipitating agent solution (42\% v/v PEG 600, $0.2 \mathrm{M}$ imidazole malate at $\mathrm{pH} 5.5$ ) and covered with paraffin oil (Hampton Research Corporation, HR3-411, USA) to prevent evaporation. Volumes from 2 to $30 \mu \mathrm{L}$ were tested using 24 well plates. For the batch method, the reservoir was left empty. Precipitates were obtained by the same procedure except using a molar ratio of $1: 1$ Cter HsCen2/P17-XPC solution and the same precipitating agent conditions. Precipitates appeared at $277 \mathrm{~K}$ after one week.

Microcrystals for Solid-State NMR. HEW Lysozyme. Two stock solutions of 37 and $70 \mathrm{mg} \cdot \mathrm{mL}^{-1}$ were prepared in $100 \mathrm{mM}$ sodium acetate at $\mathrm{pH} 4.5$. Duplicate drops of 4 to $40 \mu \mathrm{L}$ with increments of 4 $\mu \mathrm{L}$ were deposited on a sitting-drop 24 wells plate for solutions of 37 and $70 \mathrm{mg} \cdot \mathrm{mL}^{-1}$. The precipitating agent was composed of $33 \% \mathrm{w} / \mathrm{v}$
PEG $2 \mathrm{k}, 6 \mathrm{mM}$ trisodium citrate, and $100 \mathrm{mM}$ sodium acetate at $\mathrm{pH}$ 4.5 and was added only to the reservoir $(700 \mu \mathrm{L})$ and not to the drop containing the protein. The boxes were prepared and stored in a cold room at $277 \mathrm{~K}$. Crystals obtained by the sitting-drop vapor-diffusion method had average dimensions of $20 \times 20 \times 20 \mu \mathrm{m}$ (see Figure 1a). Drops with small volumes started to nucleate after 2 days. The nucleation was allowed to continue for 60 days. A total volume of 288 $\mu \mathrm{L}$ of an aqueous suspension of lysozyme microcrystals was obtained by collecting drops of 2 and $4 \mu \mathrm{L}$. The microcrystals were centrifuged and the supernatant was discarded. The crystallization yield was estimated by (1) measuring the absorbance at $280 \mathrm{~nm}$ of the supernatant solution and comparing the obtained concentration of noncrystallized protein to that of the stock solution and (2) dissolving a small quantity of microcrystals with $6 \mathrm{M}$ guanidinium hydrochloride and measuring the absorbance of the solution at $280 \mathrm{~nm}$. The yields obtained by these two methods were 79 and $86 \%$, respectively. The lysozyme microcrystals were then centrifuged in a $4 \mathrm{~mm} \mathrm{ZrO}_{2}$ rotor with aliquots of $10 \mu \mathrm{L}$ at $8500 \mathrm{rpm}$ for $15 \mathrm{~min}$ at $277 \mathrm{~K}$. The rotor was stored at $277 \mathrm{~K}$ without sealing the cap. The mass of microcrystalline lysozyme was estimated to be about $50 \mathrm{mg}$ in the rotor. All MAS rotors used in this work were made of zirconium dioxide and purchased from the same provider (Cortecnet, France).

Cter HsCen2/P17-XPC Protein-Peptide Complex. The precipitating agent was composed of $42 \% \mathrm{v} / \mathrm{v}$ PEG 600 in $0.2 \mathrm{M}$ imidazole malate at $\mathrm{pH}$ 5.5. A crystalline mixture of a majority of urchin-like crystals and a minority of plate-like crystals was obtained from a stock solution of the protein complex by the sitting-drop vapor-diffusion method at $277 \mathrm{~K}$ using 1 to $20 \mu \mathrm{L}$ of the stock solution as described in the Low-Salt Screening Conditions section. Urchin-like crystals appeared after $24 \mathrm{~h}$ and did not evolve after 2 days. A total volume of $678 \mu \mathrm{L}$ of a suspension of microcrystals was collected. The crystallization yield was estimated to be between $50-80 \%$ as determined for the lysozyme microcrystals. Subsequently, about 19 $\mathrm{mg}$ of microcrystals were used to fill both 1.3 and $2.5 \mathrm{~mm}$ rotors. The filling of the small diameter MAS rotors was assisted by ultracentrifugation with home-built adaptors. ${ }^{42}$ 
The plate-like crystals were obtained by the batch method by mixing equal volumes $(2-50 \mu \mathrm{L})$ of stock complex solution and precipitating agent on a cell-culture plate with 96 wells. The box was refrigerated at $277 \mathrm{~K}$. Plate-like crystals appeared after one day and the crystallization lasted 3 days. A total volume of $1066 \mu \mathrm{L}$ was collected. The crystallization yields are similar to those observed in the case of urchinlike crystals. Finally, we obtained about $25 \mathrm{mg}$ of plate-like crystals, which were partly used to fill a $2.5 \mathrm{~mm}$ MAS rotor. The rest of the aqueous microcrystalline suspension was stored at $277 \mathrm{~K}$ for several months and turned to a white powder that was used to fill a $1.3 \mathrm{~mm}$ MAS rotor as described above.

LCter HsCen2 $\left(M^{84}-Y^{172}\right)$. The protein was obtained as a proteolysis product after overexpression of the integral Human centrin 2 as described previously. ${ }^{39,40}$ Two stock solutions of LCter HsCen 2 with final concentrations of 1.5 and $3 \mathrm{mM}$ were prepared and stored at 277 $\mathrm{K}$. Crystallization conditions were tested using the sitting-drop vapordiffusion method described above on 24-well plates containing doublets of $2 \mu \mathrm{L}$ drops of the protein solution. For each protein concentration, two boxes were prepared at room temperature and stored at 277 and $290 \mathrm{~K}$. After 14 days, urchin-like crystals and fine needles appeared with concentrations of PEG 600 of 15, 24, and $42 \%$ $\mathrm{v} / \mathrm{v}$ at $290 \mathrm{~K}$.

Collection of Microcrystals for Solid-State NMR. Collecting microcrystals requires washing every single well with appropriate precipitating agents. This is a tedious and time-consuming task. In fact, the microcrystals tend to stick on the surface of the well and a thin cat moustache is used to displace them from the surface of the well by manipulating under binoculars. These manipulations were repeated three times in order to gather as many crystals as possible. The microcrystals are then pipetted carefully using pipet tips cut at the end with a scalpel. Fast pipetting can trigger the precipitation of the protein. Therefore, the scaling-up of the crystallogenesis was performed in order to minimize losses in time, quality, and quantity of the crystals.

Scaling-up Production of Microcrystals. For the sitting-drop vapor-diffusion method, the sitting-drop well was replaced by a watch glass and the reservoir well by a Petri box. This permitted to scale-up the preparation to $200 \mu \mathrm{L}$ of protein or complex solution. Bigger stock-solution volumes $(20,50,100$, and $400 \mu \mathrm{L})$ were undertaken with 9-well glass plates (Hampton Research Corporation, USA) immobilized by polystyrene and placed into a Sandwich box (from the same provider) containing $25 \mathrm{~mL}$ of precipitating agent. Boxes were stored at 277, 290, or $305 \mathrm{~K}$. Microcrystals appeared only in the case of lysozyme (37 and $100 \mathrm{mg} \cdot \mathrm{mL}^{-1}$ ) using drops of 100 and $200 \mu \mathrm{L}$ on a watch glass after $24 \mathrm{~h}$ at $305 \mathrm{~K}$. The watch glass was placed inside a plastic box containing $7.5 \mathrm{~mL}$ of precipitating agent and covered with a Petri dish lid but not sealed. In the case of the highly concentrated lysozyme solution, crystals appeared after 4 days, whereas the crystals from the low concentrated lysozyme solution appeared only after 6 days. It is noteworthy that no precipitating agent needed to be added to the HEW lysozyme drops, thus confirming the very low-salt conditions of HEW lysozyme crystallogenesis even for larger volumes. On the contrary, a precipitating agent was added to the Cter $\mathrm{HsCen} 2 /$ P17-XPC complex. Drops containing a mixture of urchin- and platelike microcrystals as well as drops composed of only plate-like microcrystals of Cter HsCen2/P17-XPC complex could be obtained in larger volumes $(50 \mu \mathrm{L})$ using $1 \mathrm{~mL}$ pipet tips that were flame-sealed and cooled. Both the complex solution and precipitating agent $(50 \mu \mathrm{L}$ of $42 \% \mathrm{v} / \mathrm{v}$ PEG 600 in $0.2 \mathrm{M}$ imidazole malate at $\mathrm{pH} 5.5$ ) were added to the drop. In order to mimic the vapor-diffusion drop-reservoir ensemble, the sealed pipet tip was plunged inside a $20 \mathrm{~mL}$ Falcon or hemolyse tube containing $2 \mathrm{~mL}$ of precipitating agent at $277 \mathrm{~K}$ for four days (see Figure 2).

For the batch method, either sealed pipet tips or microtubes (Eppendorf type) were used and only tested for the Cter HsCen2/ P17-XPC complex crystallization. The sealed pipet tips stored at 277 and $290 \mathrm{~K}$ resulted in plate-like crystals, which could not be removed from the pipet-tip surface. In the case of microtubes, plate-like crystals were obtained after several days at $277 \mathrm{~K}$. Microcrystallization can be accelerated by seeding with microcrystals previously obtained from

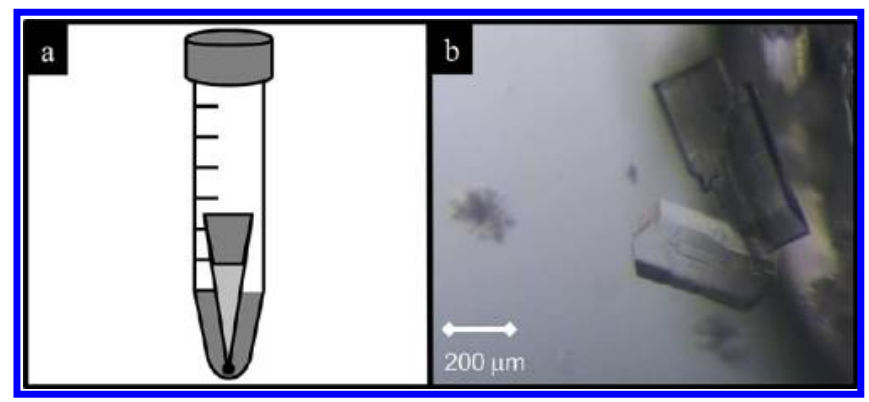

Figure 2. (a) Scheme of a sealed pipet cone containing complex solution (light gray) and precipitating agent (dark gray) in a Falcon tube, which was used as a scaling-up of the vapor-diffusion method. (b) Microcrystals obtained directly inside the sealed pipet cone.

screening low-salt conditions and crushing them inside the microtube. The plate-like crystals appeared after $24 \mathrm{~h}$ at $277 \mathrm{~K}$ and settled by gravitation.

Solid-State NMR Spectroscopy. Cross-polarization magic-angle spinning (CPMAS) spectra of carbon-13 shown in Figure 3a,d,e were obtained on a Bruker Avance III $400 \mathrm{MHz}$ wide-bore spectrometer equipped with a $4 \mathrm{~mm}$ double-resonance probe at a spinning frequency of $10 \mathrm{kHz}$ for the HEW lysozyme sample and with a 2.5 $\mathrm{mm}$ double-resonance probe at a spinning frequency of $10 \mathrm{kHz}$ for the Cter HsCen2/P17-XPC complex. The CPMAS spectra of Figure 3b,c were recorded at spinning frequencies of 22.4 and $40 \mathrm{kHz}$, respectively, on a Bruker Avance III $900 \mathrm{MHz}$ standard-bore spectrometer equipped with a $1.3 \mathrm{~mm}$ double-resonance probe. No apodization was applied prior to Fourier transform. The experiments were carried out at temperatures of $263 \mathrm{~K}\left(-10^{\circ} \mathrm{C}\right)$, according to the thermocouple, for the HEW lysozyme sample and at $277 \mathrm{~K}$ for the Cter HsCen2/P17-XPC complex.

Cross-polarization used either square or ramped pulses at the $n=$ \pm 1 Hartmann $-\mathrm{Hahn}^{43}$ conditions. The contact time was set to optimize the transfer across all regions of the spectra. Either SPINAL $64^{44}$ or PISSARRO ${ }^{45,46}$ proton decoupling schemes were applied during signal acquisition. A pulse length of $1.1 \tau_{\text {rot }}$ where $\tau_{\text {rot }}$ is the rotor period, was used for PISSARRO decoupling.

\section{RESULTS AND DISCUSSION}

Low-Salt Crystallization of HEW Lysozyme Suitable for Solid-State NMR. Several preparations of microcrystals of HEW lysozyme for solid-state NMR have been described in the literature. ${ }^{47,48}$ All have high concentrations of salt and precipitating agents. Here, we present a procedure to prepare lysozyme microcrystals with low-salt concentrations, so as to allow higher radiofrequency amplitudes, more efficient decoupling, and longer acquisition times. Indeed, the scalingup of the vapor-diffusion crystallization of HEW lysozyme in a watch glass does not require the addition of any precipitating agent to the protein solution. Only the protein buffer sodium acetate is present in the microcrystals.

As described in the experimental part, regular crystals were obtained as shown in Figure 1a. The crystals had average dimensions of $20 \times 20 \times 20 \mu \mathrm{m}$. Figure 3a shows a carbon-13 CPMAS spectrum recorded in $2.5 \mathrm{~h}$ at natural abundance exhibiting remarkable linewidths of $0.2 \mathrm{ppm}(20 \mathrm{~Hz})$ for isolated methyl groups.

The preparation of very low-salt HEW lysozyme microcrystals without the addition of any precipitating agent to the protein drop as described in the experimental section is very attractive, but unfortunately, the method is not applicable to our system of interest, the Cter HsCen2/P17-XPC complex.

Strategies and Screening of Crystallization Conditions for Cter HsCen2 Constructs. The various precipitates 


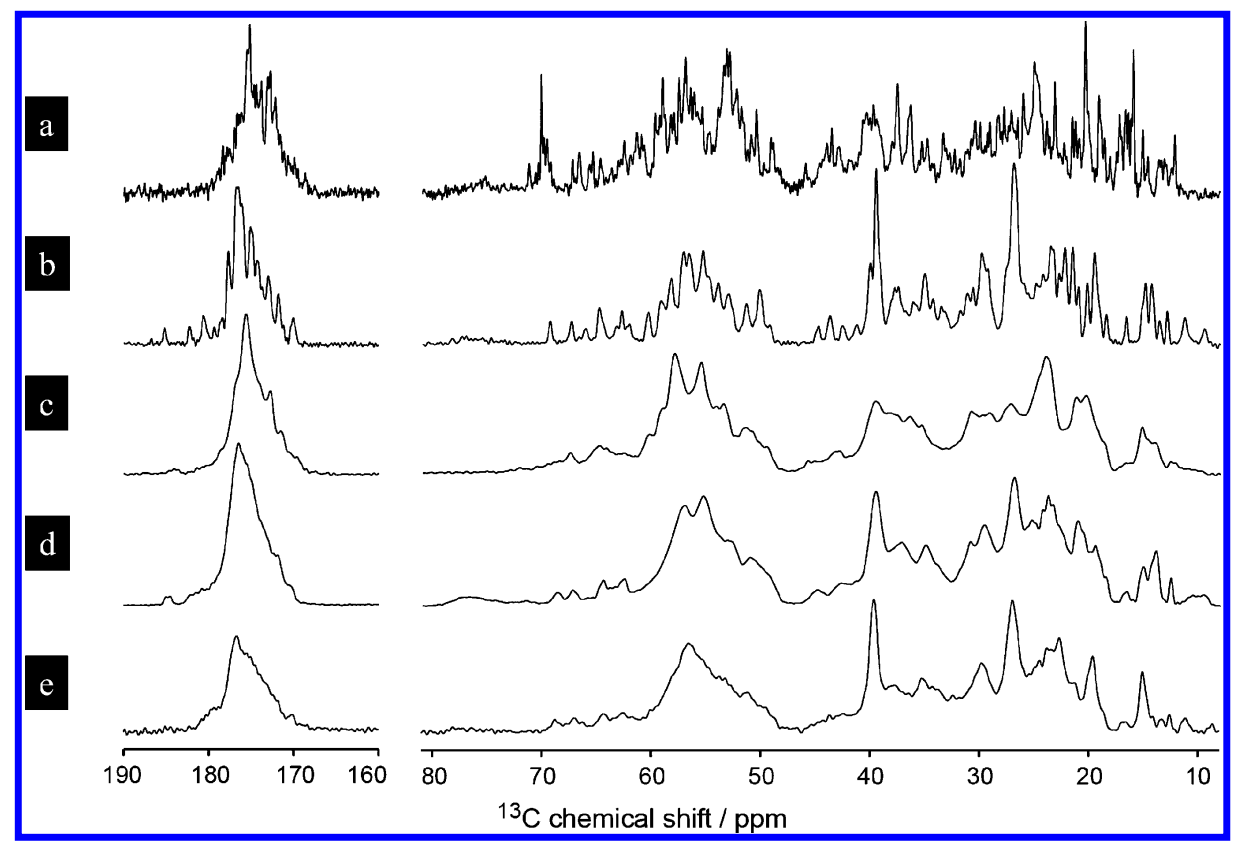

Figure $3 .{ }^{13} \mathrm{C}$ CPMAS spectra of (a) natural abundance HEW lysozyme crystals packed in a $4 \mathrm{~mm}$ rotor spinning at $10 \mathrm{kHz}$ at $9.4 \mathrm{~T}$ and of (b) platelike crystals of the complex $\mathrm{U}-{ }^{13} \mathrm{C},{ }^{15} \mathrm{~N}$-enriched Cter HsCen2/P17-XPC obtained by the batch method and stored at $277 \mathrm{~K}$ for 12 months after collection. The plate-like crystals were packed in a $1.3 \mathrm{~mm}$ rotor spinning at $22.4 \mathrm{kHz}$ at $21.1 \mathrm{~T}$. (c) Sample freshly packed after collection in a 1.3 $\mathrm{mm}$ rotor spinning at $40 \mathrm{kHz}$ at $21.1 \mathrm{~T}$ containing mainly urchin-like crystals of the $\mathrm{U}-{ }^{13} \mathrm{C},{ }^{15} \mathrm{~N}$-enriched Cter HsCen2/P17-XPC complex obtained by vapor diffusion and recorded just after collection. (d) Sample packed in a $2.5 \mathrm{~mm}$ rotor spinning at $10 \mathrm{kHz}$ at $9.4 \mathrm{~T}$ consisting of urchin-like crystals obtained by vapor diffusion and recorded just after collection. (e) Sample packed in a $2.5 \mathrm{~mm}$ rotor spinning at $10 \mathrm{kHz}$ at $9.4 \mathrm{~T}$ containing mainly plate-like crystals of the $\mathrm{U}-{ }^{13} \mathrm{C},{ }^{15} \mathrm{~N}$-enriched Cter HsCen2/P17-XPC complex obtained by the batch method and recorded after collecting the crystals.

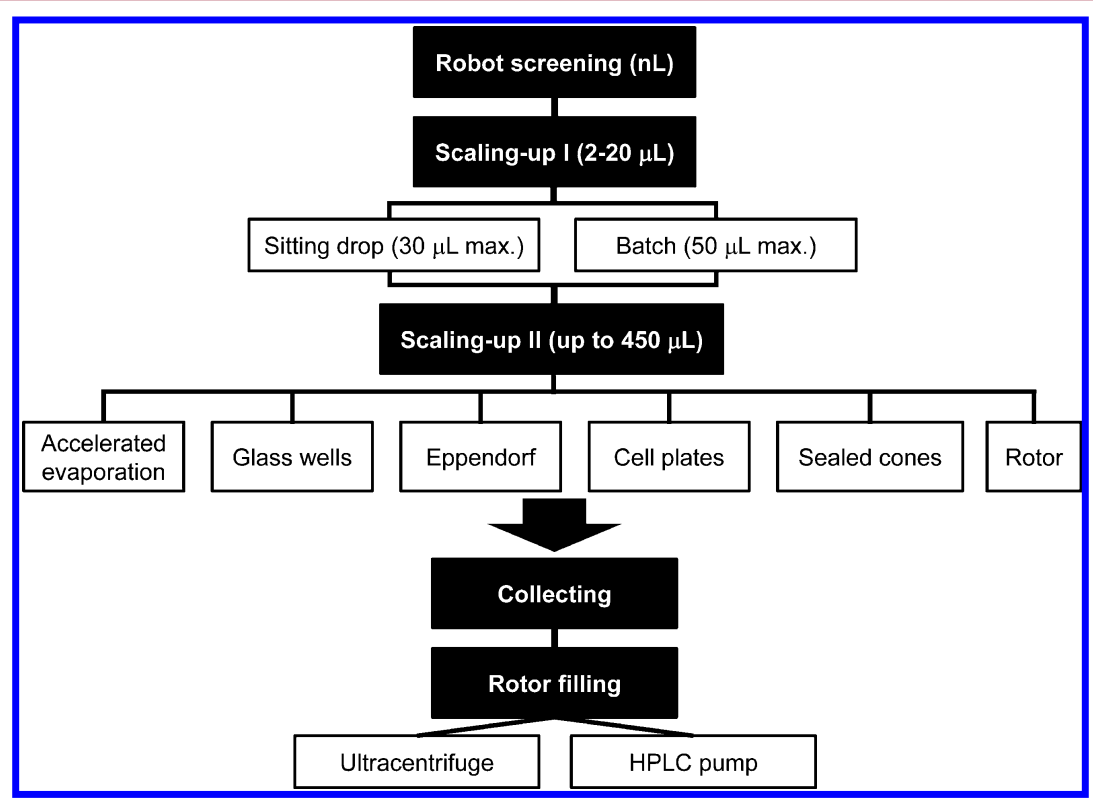

Figure 4. Protocol for obtaining large-scale microcrystals and filling rotors for solid-state NMR.

of the Cter HsCen2/P17-XPC complex did not yield any structured objects in the nanometer range as checked by electron microscopy. It is therefore difficult to draw conclusions about the crystallinity of the precipitates of the complex considering the dilution steps that could damage the fragile crystals. The precipitates may be intrinsically unstructured. In summary, electron microscopy does not allow the determination of the degree of crystallinity of precipitates and nanocrystals of delicate biological systems like the Cter HsCen2/P17-XPC complex.
X-ray powder diffraction has been used previously to determine the degree of crystallinity of nanocrystals of ubiquitin, lysozyme, ribonuclease A, streptavidin, and cytochrome $\mathrm{C}^{48}$ The nanocrystalline materials were produced by rapid bulk crystallization, while scaling-up was performed directly, by using a centrifugal evaporator, from the optimized precipitation conditions previously obtained by initial screening. Unfortunately, this second approach is not applicable to delicate systems such as protein complexes. 


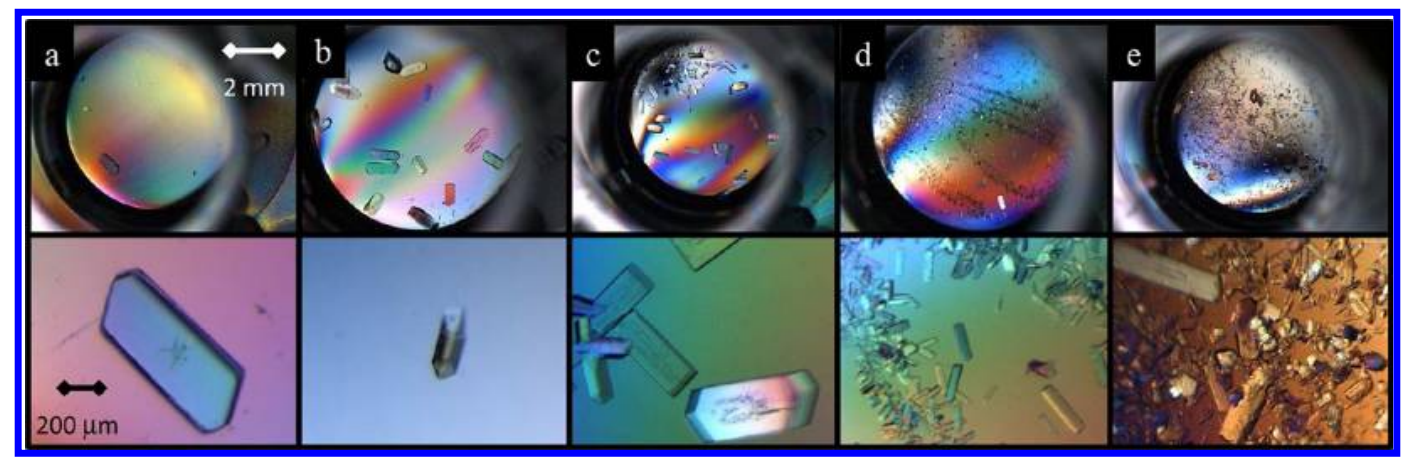

Figure 5. Plate-like crystals of the complex Cter HsCen2/P17-XPC (molar ratio protein/peptide 1:2) obtained by the batch method. Each drop contained $150 \mu \mathrm{L}$ of mother solution $\left(34 \mathrm{mg} \cdot \mathrm{mL}^{-1}\right.$ in $20 \mathrm{mM}$ Tris at $\mathrm{pH} 7.5,400 \mathrm{mM} \mathrm{NaCl}, 10 \mathrm{mM} \mathrm{CaCl}$ ) and $150 \mu \mathrm{L}$ of precipitating agent $(42 \%$ v/v PEG 600 in $0.2 \mathrm{M}$ imidazole malate $\mathrm{pH} 5.5$ ) covered by $50 \mu \mathrm{L}$ of paraffin oil to prevent evaporation. (a,b) Drops with only few single crystals suitable for X-ray diffraction. (c) Drop with many crystals obtained by seeding with $2 \mu \mathrm{L}$ of crushed plate-like crystals. (d,e) Drops with numerous microcrystals obtained either by seeding with a cat moustache, which was in contact with plate-like crystals (d), or by simple mixing with a cat moustache (e). The lower panels show zooms on crystals in the upper panels.

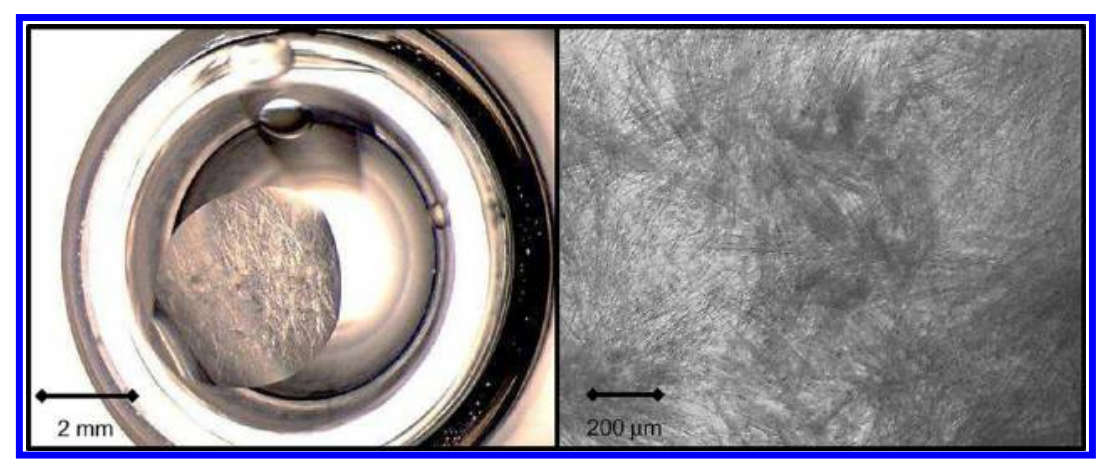

Figure 6. Needle-like crystals of LCter HsCen2 obtained by vapor diffusion using $2 \mu \mathrm{L}$ mother solution $\left(31 \mathrm{mg} \cdot \mathrm{mL}^{-1}\right.$ in $20 \mathrm{mM} \mathrm{Tris} \mathrm{at} \mathrm{pH} 7.5$, 400 $\mathrm{mM} \mathrm{NaCl}, 10 \mathrm{mM} \mathrm{CaCl}$ ) and $2 \mu \mathrm{L}$ of precipitating agent (42\% v/v PEG 600 in $0.2 \mathrm{M}$ imidazole malate at pH 5.5) at $290 \mathrm{~K}$ after 2 weeks.

We therefore focused our efforts on the production of the protein-peptide complex microcrystals by adapting the singlecrystal protocol to large-scale production intended for solidstate NMR applications. The different steps and strategies followed to obtain microcrystals of the Cter HsCen2/P17-XPC complex in sufficient quantity for solid-state NMR are illustrated in Figure 4. The same method can be applied to other biological systems. The preparation of microcrystals of the protein complex introduces additional optimization parameters, as both the complex formation and crystallization conditions need to be scaled-up in order to yield sufficient quantities of homogeneous microcrystals to fill NMR rotors.

As illustrated in Figure 4, the first step is the screening of crystallization conditions that are suitable for complex formation at low-salt concentrations. Screening is done in two stages. The first screening uses a high-throughput robot for crystallization with nanodrops allowing one to select efficient precipitating agents with suitable buffers to form microcrystals. Selection of the appropriate condition is based on both successful crystallization and a high concentration of microcrystals. This stands in contrast to crystallization protocols for X-ray diffraction where single crystals are selected for the regularity of their growth and easy handling. The primer conditions are targeted as for the crystallization of single crystals. This includes the control of the protein buffer and peptide buffer solutions (concentrations, $\mathrm{pH}$, temperature, nature of the buffer, and order of mixture), as well as the molar ratio of the partners in the complex, the nature of the precipitating agent and its buffer solution and $\mathrm{pH}$, the temperature during crystal growth, and the method of crystallization. The batch method has two major advantages over the vapor-diffusion or dialysis methods: (i) the scaling-up is easily implemented, and (ii) it allows an exact initial supersaturation, in contrast to vapor-diffusion or dialysis methods where the crystallization process starts from an unsaturated state and evolves toward a supersaturated state. Consequently, the supersaturation at which crystals are formed is unknown in this case. Previous studies ${ }^{49}$ of the nucleation behavior of lysozyme crystals have shown that the number of crystals increases with increasing supersaturation and temperature. However, the most relevant variable is $\mathrm{pH}$ since an increase in the size and the number of crystals is observed with decreasing $\mathrm{pH}$. Results on lysozyme showed a change of 2 orders of magnitude in the number of crystals over a $\mathrm{pH}$ range between 4.0 and 5.2. A so-called storage effect (aging) of the protein solution was also shown to influence the nucleation process, therefore, the size and number of the crystals. ${ }^{50,51}$ Hence, the number of crystals increases while their size decreases with storage time of the protein solution. This effect was ascribed to the presence of fungi that multiply in the stored protein solution. The quality of the crystals is expected to deteriorate, at least for X-ray diffraction studies using crystals aged protein solutions. For the crystallization preparations presented in this work, the protein, peptide, or complex solutions were freshly prepared prior to crystallization.

Successful microcrystallization of the complex Cter HsCen2/ P17-XPC was observed for a 1:2 molar ratio of protein/peptide Cter HsCen2/P17-XPC. Plate-like (Figure 1b) and urchin-like 
microcrystals (Figure 1c) and mixtures thereof (Figure 1d) were obtained (see Experimental Procedures). Our studies showed that an excess of peptide was necessary. These conditions were found by screening in the vicinity of the conditions described in the literature for solution-state $\mathrm{NMR}^{33,52}$ and crystallogenesis data on Human centrin 2 complexes. $^{53,54}$ Note that both calcium-binding sites of Cter HsCen 2 must be saturated. In the case of partial saturation, a mixture of different forms is obtained, impeding complex crystallization. Figure 5a shows a single crystal of the complex perfectly adapted for an X-ray experiment. Figure $5 \mathrm{~b}$ illustrates a drop with single crystals not optimized for solid-state NMR collection. One can induce/accelerate the crystallogenesis either by microseeding with bits of crystal (Figure 5c), by seeding with a cat moustache that was previously in contact with crystals (Figure 5d), or by crushing the crystals (Figure 5e). Clearly, drops containing numerous microcrystals (Figure $5 \mathrm{c}-\mathrm{e})$ are more favorable to the collection stage.

Other types of microcrystals were obtained using a different construct of the C-terminal domain of HsCen2 (LCter HsCen2 $\mathrm{M}^{84}-\mathrm{Y}^{172}$ ) that contains 10 additional residues. The structure of the LCter HsCen 2 was previously determined by interpreting interproton distances in NOESY experiments. ${ }^{39}$ The structure shows that the additional 10 residues are located in the P17XPC peptide binding site. In this case, the crystallization was easier because the same buffer and precipitating agent as for Cter HsCen2 have been successfully used. Fine needles (see Figure 6) appeared after 14 days of incubation at $290 \mathrm{~K}$ using the sitting-drop vapor-diffusion method. These needles were stable over several months at $290 \mathrm{~K}$, but unfortunately, attempts to collect them failed. Because of their strong affinity for the plastic well, they degraded during collection. Furthermore, the needles appeared to have a low density and were difficult to centrifuge, and subsequently, the handling of such needles for solid-state NMR was problematic.

Scaling-up Crystallogenesis for the Complex Cter HsCen2/P17-XPC. Obviously, scaling-up the crystallization volume is a challenge that needs to be overcome to produce amounts of microcrystals that are sufficient to fill a MAS rotor for solid-state NMR. The quantity of protein microcrystals required is on the order of 5-12 mg since a $1.3 \mathrm{~mm}$ MAS rotor has a volume of $5 \mu \mathrm{L}$ and a $2.5 \mathrm{~mm}$ rotor a volume of $12 \mu \mathrm{L}$. The exact mass of microcrystals is difficult to determine since the samples contain substantial amounts of precipitating agent and buffer. The use of a larger number of drops is not advisible, not only from a manipulation point of view but also because the integrity of the microcrystals might suffer during their collection as described in the experimental part. Moreover, the wells of the drops must be washed with precipitating agent in order to collect as many microcrystals as possible. Adding 3fold volumes of precipitating agent to the collected drops disrupts the subtle equilibrium between the concentrations of the complex and the precipitating agent achieved at the beginning of the batch method or at the end of nucleation in the vapor-diffusion method. This addition can affect the evolution of stored microcrystals as will be illustrated later with the NMR spectra. Therefore, several strategies have been tested in order to minimize the number of manipulations of microcrystals for vapor-diffusion and batch methods.

For the Cter HsCen2/P17-XPC complex, the best and most straightforward approach was to crystallize directly inside a microtube via the batch method after microseeding (see Experimental Procedures) as shown in Figure 7. This technique

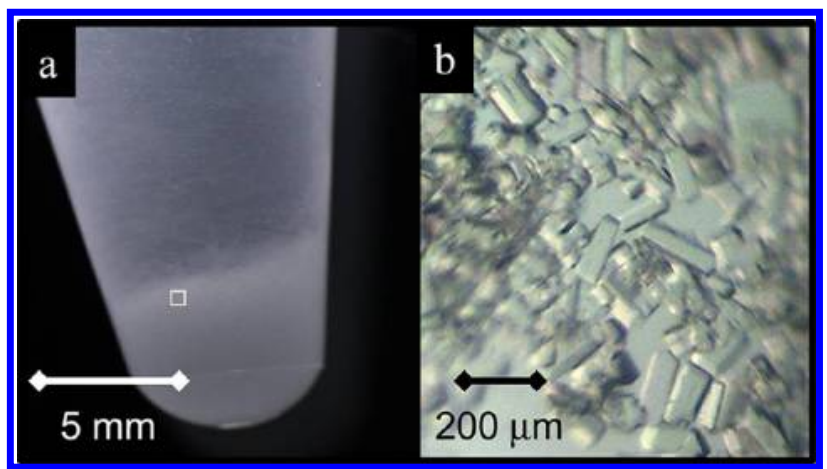

Figure 7. (a) Plate-like crystals of the complex Cter HsCen2/P17XPC (molar ratio protein/peptide 1:2) obtained in a $1.5 \mathrm{~mL}$ Eppendorf at $277 \mathrm{~K} 48 \mathrm{~h}$ after mixing $150 \mu \mathrm{L}$ of mother solution (34 $\mathrm{mg} \cdot \mathrm{mL}^{-1}$ in $20 \mathrm{mM}$ Tris at $\mathrm{pH} 7.5,400 \mathrm{mM} \mathrm{NaCl}, 10 \mathrm{mM} \mathrm{CaCl}$ ) and $150 \mu \mathrm{L}$ of precipitating agent (42\% v/v PEG 600 in $0.2 \mathrm{M}$ imidazole malate $\mathrm{pH}$ 5.5) covered with $50 \mu \mathrm{L}$ of paraffin oil to prevent evaporation. The picture in panel $\mathrm{b}$ corresponds to a magnification of 10 of the square (white line) in panel a.

permits one to eliminate the supernatant and to directly obtain a concentrated suspension of microcrystals without prior treatment or addition of any other component, thus minimizing the handling of these fragile microcrystals. Interestingly, the plate-like crystals did not stick to the microtube.

Filling Small Diameter Rotors for ssNMR with Cter HsCen2/P17-XPC Microcrystals. The last step of the sample preparation protocol is the transfer of the microcrystals to solidstate NMR sample holders, i.e., MAS rotors. The most challenging is the filling of small outer diameter ( 1.3 and 2.5 $\mathrm{mm}$ ) rotors. This requires homogeneous packing of the microcrystals to achieve good filling factors and to allow spinning at high frequencies (up to $65 \mathrm{kHz}$ in $1.3 \mathrm{~mm}$ MAS rotors). Indeed, the NMR signal is proportional to the number of spins and therefore to the quantity of material. Böckmann et al. described adaptors for packing MAS rotors with an ultracentrifuge. ${ }^{42}$ We used ultracentrifugation in home-built adaptors to fill rotors with microcrystals of the Cter HsCen2/ P17-XPC complex.

We also developed a new method that uses an HPLC pump to pack MAS rotors with microcrystals retained by a frit with $0.2 \mu \mathrm{m}$ porosity (Figure 8 ). The empty rotor, a cylinder that must be open on both sides, is placed inside an empty HPLC column with an inner diameter that fits the outer diameter of the rotor. The suspension of microcrystals in the precipitating agent is pumped through the assembly. This method is successful when packing robust microcrystals of proteins such as HEW lysozyme. Figure 8c shows MAS rotors packed with HEW lysozyme microcrystals using the HPLC pump. This method could also be applied to any other system in order to fill solid-state NMR rotors. For example, one could concentrate fibers or any kind of biopolymers if one utilizes a suitable solvent to pack the rotor without solubilizing the objects of interest.

Solid-State NMR Carbon-13 Spectra of Lysozyme and Cter HsCen2/P17-XPC. Solid-state NMR spectroscopy is very sensitive to the homogeneity of the sample. If a solid sample contains different species (i.e., aggregates, precipitates, or different crystalline forms), small variations in chemical shifts will lead to broad resonances. As a consequence, site-specific assignment will be challenging or impossible. Solid-state carbon-13 CPMAS NMR spectra were recorded by cross- 


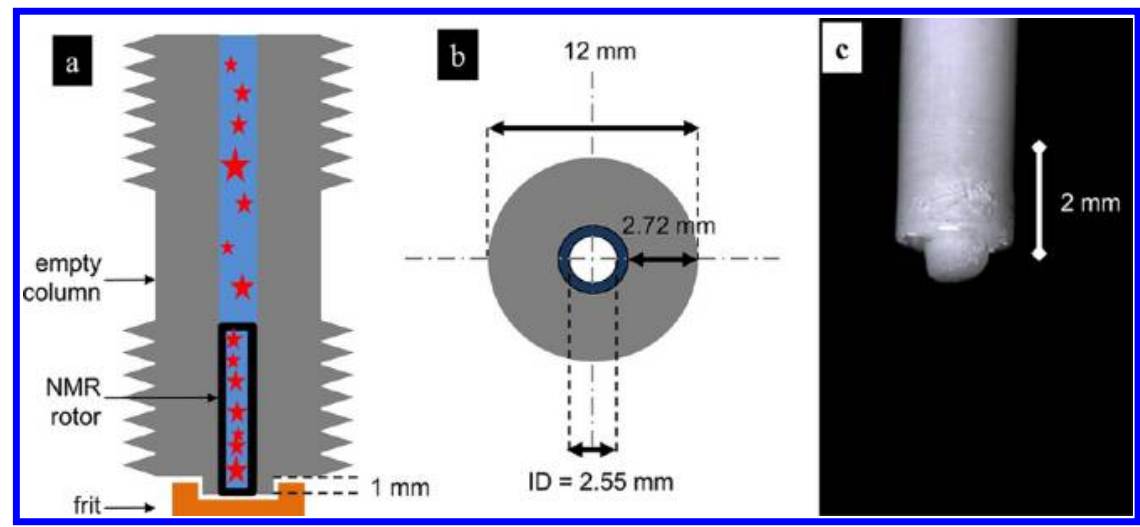

Figure 8. (a) Scheme for filling an NMR rotor using an HPLC system. An adaptor consisting of an empty rotor inserted into an HPLC column is required. The precipitating agent (in blue) is pushed through the rotor by the HPLC pump, while the microcrystals (red stars) are retained by the frit. (b) Adaptor scheme seen from the top with its dimensions. (c) Side-view of a $2.5 \mathrm{~mm}$ MAS rotor containing microcrystals of HEW lysozyme packed by the HPLC method.

polarization from protons to carbons to enhance the sensitivity of the low-gamma nuclei, while spinning the sample at the magic angle. Figure 3a,b exhibits remarkably narrow resonances with linewidths of $0.3-0.5 \mathrm{ppm}$ for microcrystals of (a) HEW lysozyme and (b) Cter HsCen2/P17-XPC complex. Rotors packed immediately after harvesting of the microcrystals resulted in spectra with broad signals due very likely to the superposition of contributions not only from microcrystals but also from precipitates and aggregates. Microcrystals stored for several months at $277 \mathrm{~K}$ yielded remarkably narrow linewidths of $0.3 \mathrm{ppm}(\sim 67 \mathrm{~Hz})$ for isolated methyl groups in the complex (Figure $3 b$ ), therefore, attesting for an evolution toward more homogeneous samples with time. These results will be further exploited for solid-state NMR assignment of the complex, and followed by site-specific studies in the solid state.

\section{CONCLUSIONS}

The optimum conditions for the formation of microcrystals that satisfy the requirements for solid-state NMR spectroscopy depend on a variety of factors. Minimum manipulation of the microcrystals and leaving of the samples for several months at $277 \mathrm{~K}$ allow one to obtain highly resolved NMR spectra. Among the three systems investigated, the crystallization of the Cter HsCen2/P17-XPC complex was the most challenging because protein/peptide molar ratio, $\mathrm{pH}$, temperature, precipitating agent, and crystallization method all influence the outcome. To our knowledge, this is the first microcrystalline protein-peptide complex studied by solid-state NMR. We have designed a device for filling MAS rotors with protein microcrystals that uses basic HPLC equipment. The preparation protocols described in this work are not limited to solidstate NMR but can also be used for other spectroscopic and biophysical techniques.

\section{AUTHOR INFORMATION}

\section{Corresponding Author}

*E-mail: monique.chan-huot@curie.fr.

\section{Notes}

The authors declare no competing financial interest.

\section{ACKNOWLEDGMENTS}

We thank S. Marco for electron microscopy experiments, I. Gallay for stimulating discussions and precious help with the preparation of HEW lysozyme microcrystals under low-salt conditions, D. Picot and P. Tekely for stimulating discussions, M. Weingarth for his implication in the initial stages of the project, A. Böckmann for help with the transfer of microcrystals into NMR rotors, J. Trébosc for help with the setup of the NMR experiments in Lille, and S. Jannin together with the EPFL workshop for building the ultracentrifuge adaptors. Financial support from the Agence Nationale de la Recherche (Project 'FastSpinProts' ANR-09-BLAN-0111-01) and the network of Très Grands Equipements de Résonance Magnétique Nucléaire à Très Hauts Champs (TGE RMN THC), CNRS 3050, is gratefully acknowledged. We thank J. A. Marquèz for access to the High Throughput Crystallization (HTX) platform at European Molecular Biology Laboratory $(\mathrm{EMBL})$ in Grenoble.

\section{LIST OF ABBREVIATIONS}

Cter HsCen2, C-terminal domain Human centrin 2 protein; LCter HsCen2, lengthened C-terminal domain Human centrin 2 protein; XPC, Xeroderma Pigmentosum group C protein; HEW, Hen Egg-White; HEPES, 4-(2-hydroxyethyl)-1-piperazineethanesulfonic acid; MPD, 2-methyl-2,4-pentandiol; PEG, polyethylene glycol; NMR, nuclear magnetic resonance; ssNMR, solid-state nuclear magnetic resonance; CPMAS, cross-polarization magic-angle spinning; HPLC, high-pressure liquid chromatography

\section{REFERENCES}

(1) Basu, S. K.; Govardhan, C. P.; Jung, C. W.; Margolin, A. L. Expert Opin. Biol. Ther. 2004, 4, 301-317.

(2) Park, S.-H.; Kwon, J.-H.; Lim, S.-H.; Park, H. W.; Kim, C.-W. Int. J. Pharm. 2007, 339, 205-212.

(3) Royant, A.; Edman, K.; Ursby, T.; Pebay-Peyroula, E.; Landau, E. M.; Neutze, R. Photochem. Photobiol. 2001, 74, 794-804.

(4) Shenoy, B.; Wang, Y.; Shan, W.; Margolin, A. L. Biotechnol. Bioeng. 2001, 73, 358-369.

(5) Manning, M. C. Expert Rev. Proteomics 2005, 2, 731-743.

(6) Ganim, Z.; Chung, H. S.; Smith, A. W.; DeFlores, L. P.; Jones, K. C.; Tokmakoff, A. Acc. Chem. Res. 2008, 41, 432-441.

(7) Dai, Y.; Whittal, R. M.; Li, L. Anal. Chem. 1996, 68, 2494-2500.

(8) Cohen, S. L.; Chait, B. T. Annu. Rev. Biophys. Biomol. Struct. 2001, 30, 67-85.

(9) Tooney, N. M.; Cohen, C. Nature 1972, 237, 23-25.

(10) Schmidt, H. L. F.; Sperling, L. J.; Gao, Y. G.; Wylie, B. J.; Boettcher, J. M.; Wilson, S. R.; Rienstra, C. M. J. Phys. Chem. B 2007, $111,14362-14369$. 
(11) Kim, H.; Garavito, R.; Lal, R. Colloids Surf., B 2000, 19, 347355.

(12) McPherson A. In Methods in Macromolecular Crystallography; Johnson, L., Turk, D., Eds.; NATO Science Series, I: Life and Behavioural Sciences; IOS Press: Amsterdam, The Netherlands, 2001; Vol. 325, pp 1-8.

(13) Castellani, F.; van Rossum, B.; Diehl, A.; Schubert, M.; Rehbein, K.; Oschkinat, H. Nature 2002, 420, 98-102.

(14) Giraud, N.; Blackledge, M.; Goldman, M.; Böckmann, A.; Lesage, A.; Penin, F.; Emsley, L. J. Am. Chem. Soc. 2005, 127, 1819018201.

(15) McDermott, A. Curr. Opin. Struct. Biol. 2004, 14, 554-561.

(16) Baldus, M. Angew. Chem., Int. Ed. 2006, 45, 1186-1188.

(17) McDermott, A.; Polenova, T.; Bockmann, A.; Zilm, K.; Paulsen, E.; Martin, R.; Montelione, G. J. Biomol. NMR 2000, 16, 209-219.

(18) Pauli, J.; van Rossum, B.; Förster, H.; de Groot, H. J.; Oschkinat, H. J. Magn. Reson. 2000, 143, 411-416.

(19) Böckmann, A.; Lange, A.; Galinier, A.; Luca, S.; Giraud, N.; Juy, M.; Heise, H.; Montserret, R.; Penin, F.; Baldus, M. J. Biomol. NMR 2003, 27, 323-339.

(20) Igumenova, T.; McDermott, A.; Zilm, K.; Martin, R.; Paulson, E.; Wand, A. J. Am. Chem. Soc. 2004, 126, 6720-6727.

(21) Franks, T. W.; Zhou, D. H.; Wylie, B. J.; Money, B. G.; Graesser, D. T.; Frericks, H. L.; Sahota, G.; Rienstra, C. M. J. Am. Chem. Soc. 2005, 127, 12291-12305.

(22) Pintacuda, G.; Giraud, N.; Pierattelli, R.; Böckmann, A.; Bertini, I.; Emsley, L. Angew. Chem., Int. Ed. 2007, 46, 1079-1082.

(23) Nadaud, P. S.; Helmus, J. J.; Jaroniec, C. P. Biomol. NMR Assign. 2007, 1, 117-120.

(24) Balayssac, S.; Bertini, I.; Bhaumik, A.; Lelli, M.; Luchinat, C. Proc. Natl. Acad. Sci. U.S.A. 2008, 105, 17284-17289.

(25) Schuetz, A.; Wasmer, C.; Habenstein, B.; Verel, R.; Greenwald, J.; Riek, R.; Böckmann, A.; Meier, B. H. ChemBioChem 2010, 11, $1543-1551$.

(26) Zhang, Y.; Doherty, T.; Li, J.; Lu, W.; Barinka, C.; Lubkowski, J.; Hong, M. J. Mol. Biol. 2010, 397, 408-422.

(27) Sperling, L. J.; Berthold, D. A.; Sasser, T. L.; Jeisy-Scott, V.; Rienstra, C. M. J. Mol. Biol. 2010, 399, 268-282.

(28) Habenstein, B.; Wasmer, C.; Bousset, L.; Sourigues, Y.; Schütz, A.; Loquet, A.; Meier, B. H.; Melki, R.; Böckmann, A. J. Biomol. NMR 2011, 51, 235-243.

(29) Kelly, A. E.; Ou, H. D.; Withers, R.; Dötsch, V. J. Am. Chem. Soc. 2002, 124, 12013-12019.

(30) Lesage, A.; Bardet, M.; Emsley, L. J. Am. Chem. Soc. 1999, 121, 10987-10993.

(31) Lange, A.; Giller, K.; Hornig, S.; Martin-Eauclaire, M.-F.; Pongs, O.; Becker, S.; Baldus, M. Nature 2006, 440, 959-962.

(32) Araki, M.; Masutani, C.; Takemura, M.; Uchida, A.; Sugasawa, K.; Kondoh, J.; Ohkuma, Y.; Hanaoka, F. J. Biol. Chem. 2001, 276, 18665-18672.

(33) Kateb, F.; Abergel, D.; Blouquit, Y.; Duchambon, P.; Craescu, C.; Bodenhausen, G. Biochemistry 2006, 45, 15011-15019.

(34) Edelhoch, H. Biochemistry 1967, 6, 1948-1954.

(35) Gill, S. C.; von Hippel, P. H. Anal. Biochem. 1989, 182, 319326.

(36) Pace, C. N.; Vajdos, F.; Fee, L.; Grimsley, G.; Gray, T. Protein Sci. 1995, 4, 2411-2423.

(37) Gasteiger, E.; Hoogland, C.; Gattiker, A.; Duvaud, S.; Wilkins, M. R.; Appel, R. D.; Bairoch, A. In Protein Identification and Analysis Tools on the ExPASy Server; Walker, J. M., Ed.; Humana Press: New York, 2005.

(38) Munier, H.; Gilles, A. M.; Glaser, P.; Krin, E.; Danchin, A.; Sarfati, R; Barzu, O. Eur. J. Biochem. 1991, 196, 469-474.

(39) Matei, E.; Miron, S.; Blouquit, Y.; Duchambon, P.; Durussel, I.; Cox, J.; Craescu, C. Biochemistry 2003, 42, 1439-1450.

(40) Durussel, I.; Blouquit, Y.; Middendorp, S.; Craescu, C. T.; Cox, J. A. FEBS Lett. 2000, 472, 208-212.

(41) Dimasi, N.; Flot, D.; Dupeux, F.; Márquez, J. A. Acta Crystallogr., Sect. F: Struct. Biol. Cryst. Commun. 2007, 63, 204-208.
(42) Böckmann, A.; Gardiennet, C.; Verel, R.; Hunkeler, A.; Loquet, A.; Pintacuda, G.; Emsley, L.; Meier, B. H.; Lesage, A. J. Biomol. NMR 2009, 45, 319-327.

(43) Hartmann, S.; Hahn, E. Phys. Rev. 1962, 128, 2042-2053.

(44) Fung, B.; Khitrin, A. K.; Ermolaev, K. J. Magn. Reson. 2000, 1-5.

(45) Weingarth, M.; Tekely, P.; Bodenhausen, G. Chem. Phys. Lett. 2008, 466, 143-147.

(46) Weingarth, M.; Bodenhausen, G.; Tekely, P. J. Magn. Reson. 2009, 199, 238-241.

(47) Krushelnitsky, A.; Gogolev, Y.; Golbik, R.; Dahlquist, F.; Reichert, D. Biochim. Biophys. Acta, Proteins Proteomics 2006, 1764, $1639-1645$

(48) Martin, R.; Zilm, K. J. Magn. Reson. 2003, 165, 162-174.

(49) Judge, R. A.; Jacobs, R. S.; Frazier, T.; Snell, E. H.; Pusey, M. L. Biophys. J. 1999, 77, 1585-1593.

(50) Chayen, N. E.; Radcliffe, J. W.; Blow, D. M. Protein Sci. 1993, 2, 113-118.

(51) Blow, D. M.; Chayen, N. E.; Lloyd, L. F.; Saridakis, E. Protein Sci. 1994, 3, 1638-1643.

(52) Popescu, A.; Miron, S.; Blouquit, Y.; Duchambon, P.; Christova, P.; Craescu, C. T. J. Biol. Chem. 2003, 278, 40252-40261.

(53) Charbonnier, J.-B.; Christova, P.; Shosheva, A.; Stura, E.; Le Du, M.-H.; Blouquit, Y.; Duchambon, P.; Miron, S.; Craescu, C. T. Acta Crystallogr., Sect. F: Struct. Biol. Cryst. Commun. 2006, 1-3.

(54) Charbonnier, J.; Renaud, E.; Miron, S.; Ledu, M.; Blouquit, Y.; Duchambon, P.; Christova, P.; Shosheva, A.; Rose, T.; Angulo, J.; Craescu, C. T. J. Mol. Biol. 2007, 373, 1032-1046. 